\title{
CORRIGENDUM
}

\section{Imaging the adult zebrafish cone mosaic using optical coherence tomography-CORRIGENDUM}

\section{ALISON L. HUCKENPAHLER, MELISSA A. WILK, ROBERT F. COOPER, FRANCIE MOEHRING, BRIAN A. LINK, JOSEPH CARROLL, AND ROSS F. COLLERY}

doi: https://doi.org/10.1017/S0952523816000092. Published by Cambridge University Press, 17 October, 2016.

When originally published, the article by the author included the wrong information in Figure 2, panel 2B as shown on page 3 . The measurement was incorrectly listed as $257 \mu \mathrm{m}$ instead of $238 \mu \mathrm{m}$.

The authors apologize for this error.

The corrected version of Figure 2, together with the full caption are shown below.
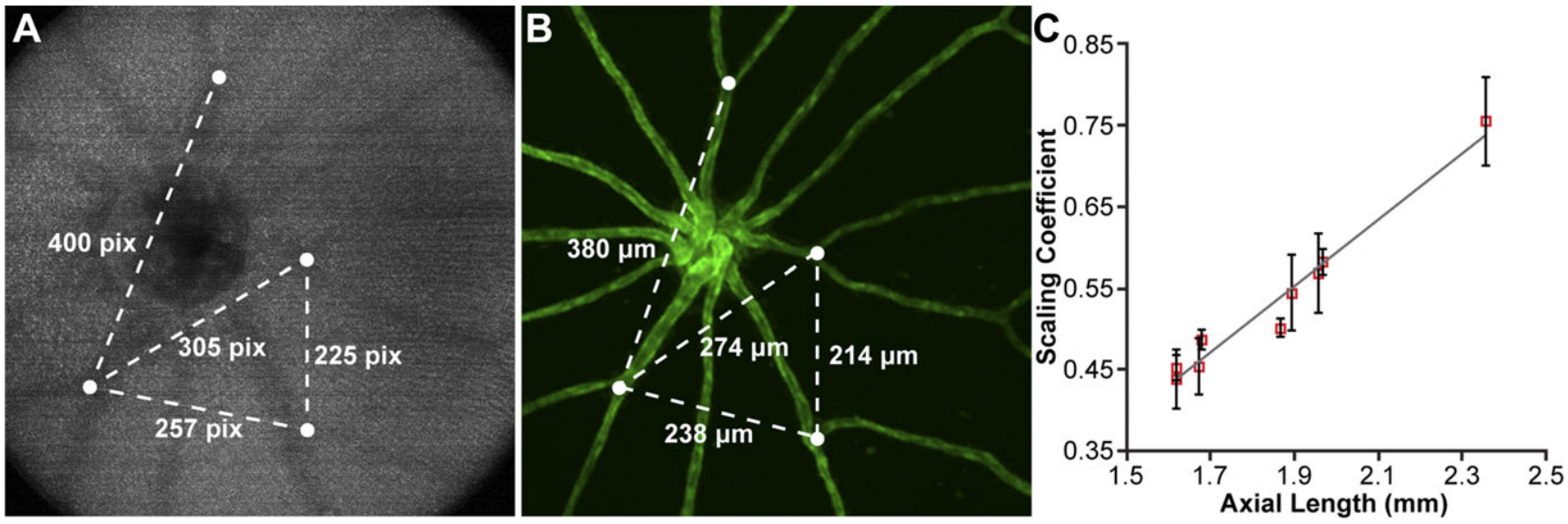

Fig. 2. Deriving the lateral scale of in vivo OCT images of the fil:eGFP zebrafish retina. (A) En face image generated by positioning the custom contour within the RNFL. Measurements (in pixels) were taken between multiple blood vessel branch points (white dots). (B) Corresponding ex vivo fluorescent microscopy image of the same retina, with measurements (in $\mu \mathrm{m}$ ) taken between the same blood vessel branch points in (A). The OCT:microscopy measurements were averaged for each eye and used to determine the size of the OCT scan in $\mu \mathrm{m}$. A scaling coefficient for each scan was calculated as the ratio between the measured size of the OCT scan to the nominal OCT scan size (in this case, $1200 \mu \mathrm{m}$ ). (C) The scaling coefficient for each scan was plotted against the axial length for that eye and fit with a linear model. Error bars represent one standard deviation for each eye.

\section{Reference}

Huckenpahler, A.L., Wilk, M.A., Cooper, R.F., Moehring, F., Link, B.A., Carroll, J., \& Collery, R.F. (2016). Imaging the adult zebrafish cone mosaic using optical coherence tomography. Visual Neuroscience, 33, E011, 1 -7. 